\title{
Apoptosis in Batch Cultures of Chinese Hamster Ovary Cells
}

\author{
J. Goswami, ${ }^{1}$ A. J. Sinskey, ${ }^{2}$ H. Steller, ${ }^{2}$ G. N. Stephanopoulos, ${ }^{1}$ \\ D. I. C. Wang ${ }^{1}$ \\ ${ }^{1}$ Department of Chemical Engineering, Massachusetts Institute of \\ Technology, 77 Massachusetts Avenue, Cambridge, Massachusetts 02139; \\ telephone: 617-253-2126; fax: 617-253-2400; e-mail: dicwang@mit.edu \\ ${ }^{2}$ Department of Biology, Massachusetts Institute of Technology, \\ Cambridge, Massachusetts
}

Received 12 December 1997; accepted 9 June 1998

\begin{abstract}
One of the main problems in the culture of Chinese Hamster Ovary ( $\mathrm{CHO}$ ) cells continues to be the inability to maintain the viability of the cultures over an extended period of time. The rapid decline in viability at the end of the culture is exacerbated by the absence of serum. In trying to reduce the extent of death in these cultures, we first tried to determine the mode of death. We found that more than $80 \%$ of the cells in a standard serum-free batch culture of $\mathrm{CHO}$ cells in suspension died via apoptosis - as evidenced by condensed chromatin and the appearance of a characteristic DNA ladder. Furthermore, when protein synthesis was inhibited using cycloheximide, the cells underwent rapid apoptosis indicating that death proteins were present in greater abundance than survival proteins in our $\mathrm{CHO}$ cells. Cell lysate from $\mathrm{CHO}$ cells showed evidence of cysteine protease (caspase) activity. Caspases of the Interleukin-1- $\beta$ Converting Enzyme (ICE) family, e.g., CPP32, Mch-1, etc., have been implicated in the apoptotic process. Surprisingly, a caspase peptide inhibitor, $N$-benzyloxycarbonylVal-Ala-Asp-fluoro-methyl-ketone (z-VAD.fmk), was unable to substantially extend the life of a serum-free batch culture of $\mathrm{CHO}$ cells. In addition, z-VAD.fmk was only marginally able to extend viability in response to withdrawal of growth and survival factors, insulin and transferrin. In both these instances, z-VAD.fmk was able to prevent cleavage of caspase substrates, but not protect cells from death. However, we found that bcl-2 expression was able to significantly extend viabilities in $\mathrm{CHO}$ batch culture. Bcl-2 expression also substantially extended the viability of cultures in response to insulin and transferrin withdrawal. These results provide interesting insights into the pathways of death in a CHO cell. (C) 1999 John Wiley \& Sons, Inc. Biotechnol Bioeng 62: 632-640, 1999.
\end{abstract}

Keywords: cell culture; Chinese Hamster Ovary; apoptosis; caspase; bcl-2

\section{INTRODUCTION}

Chinese Hamster Ovary (CHO) cells are being increasingly used in industry to manufacture complex proteins for both therapeutic and diagnostic purposes. One of the major costs

Correspondence to: Daniel Wang

Contract grant sponsors: National Science Foundation; MIT-Merck Fellowship

Contract grant number: EEC-8803014 of manufacturing these proteins is the cost of downstream purification. These costs can be reduced to a certain extent by maintaining a high density of viable and productive cells in culture for an extended period of time. Suspension culture partially achieves the first goal by allowing higher cell densities. However, in the case of $\mathrm{CHO}$ cells, suspension culture also necessitates the removal of serum from the medium. The removal of serum makes the cells more susceptible to death (Zhang et al., 1995; Ruoslahti and Reed, 1994).

Our study was performed to determine whether necrosis or apoptosis is the mode of death in serum-free suspension $\mathrm{CHO}$ cultures in the context of conflicting reports in literature as to the principal mode of death in CHO cells (Moore et al., 1995; Moore et al., 1997; Singh et al., 1994; Singh et al., 1997). Necrosis is a degenerative form of death caused by violent changes in the cell's environment. Apoptosis, on the other hand, is a genetically controlled death process, where the fate of the cell is determined by the relative abundance of survival and death proteins. There are several ways in which apoptosis can be morphologically differentiated from necrosis. Two of these distinguishing featuresthe condensation of chromatin and the fragmentation of interneucleosomal DNA into multiples of $180 \mathrm{bp}$ fragmentswere used in our study to detect apoptotic cells. Death by apoptosis can be triggered by much smaller levels of insults than those required to cause necrosis (Martin and Cotter, 1994). Such insults can take the form of very small changes in the environment which often cannot be detected, such as depletion of growth or survival factors from the medium.

Because apoptosis is genetically controlled, mitigating or enhancing the activity of death or survival proteins, respectively, should provide us with insights to delay apoptosis in cultures. One of the death-gene families that has recently been implicated in the apoptotic pathway in a number of cell lines, is the cysteine protease, or caspase family (Chinnaiyan and Dixit, 1996; Takahashi and Earnshaw, 1996; Thornberry and Molineaux, 1995; Wang et al., 1994). Translation of these genes produces proteases that have a cysteine residue in their active site and specifically recognize and cleave after the aspartate residues in their sub- 
strates or target proteins. One of the members of the caspase family, the CPP32 or Yama gene (Fernandes-Alnemri et al., 1995; Martin et al., 1996; Tewari et al., 1995), has been implicated in the cleavage of two proteins-Poly-ADPRibose Polymerase (PARP) (Lazebnik et al., 1994; Liu et al., 1996; Tewari et al., 1995) and Sterol-Regulatory Element Binding Proteins (SREBPs) (Wang et al., 1996). These proteins are responsible for DNA repair and cellular cholesterol homeostasis, respectively. We detected the presence of caspase activity in our $\mathrm{CHO}$ cells under normal cell culture conditions. Because the presence of caspase activity was detected, this study attempted to determine whether specifically inhibiting some of the caspases could extend the viability of batch cultures.

The commitment of a cell to apoptosis also depends on expression of survival proteins, hence, we studied the effect of constitutive overexpression of the survival protein, bcl-2, in $\mathrm{CHO}$ cells grown in suspension. Bcl-2 has been shown to protect many cell lines against apoptosis in response to a large number of apoptotic stimuli (Bissonnette et al., 1992; Chiou et al., 1994; Cuende et al., 1993; Fanidi et al., 1992; Farrow and Brown, 1996; Gottschalk et al., 1994; Hockenberry et al., 1993; Jacobson et al., 1993; Korsmeyer, 1992; Lam et al., 1994; Lotem and Sachs, 1993; Reed, 1994). Although the protective effect of bcl-2 expression is well documented, the exact biochemical pathway by which bcl-2 exerts its protective effect is not known. There have been some reports recently that show that bcl-2 (like its nematode homologue, ced-9) acts upstream of the caspase family of genes (Enari et al., 1996; Wang et al., 1996). In addition, several authors have shown that bcl-2 is effective in preventing different cell lines from death under cell-culture conditions (Itoh et al., 1995; Mastrangelo and Betenbaugh, 1998; Mastrangelo et al., 1996; Simpson et al., 1997; Singh et al., 1996; Singh et al., 1997; Suzuki et al., 1997; Terada et al., 1997). There have also been other attempts at reducing apoptosis in mammalian cell-culture systems using amino acid mixtures or chemical means (see review in Franek, 1995; Franek and Chladkova-Sramkova, 1995; Mastrangelo and Betenbaugh, 1998; Perreault and Lemieux, 1994). Our study was conducted to determine the relative effectiveness of using chemical (caspase-inhibiting peptides) and genetic (bcl-2 expression) methods in extending the life of $\mathrm{CHO}$ cells in serum-free batch culture. Also, through our experiments we sought to better understand the pathway of apoptosis in $\mathrm{CHO}$ cells.

\section{MATERIALS AND METHODS}

\section{Cell Culture}

Chinese Hamster Ovary ( $\mathrm{CHO}$ ) cells expressing $\gamma$-interferon were obtained from the Laboratory of Molecular Biology, State University of Ghent, Belgium (Scahill et al., 1983). The cells are routinely grown in suspension in serum-free RPMI medium (Sigma Chemicals) with $2.5 \mathrm{~g} / \mathrm{L}$ primatone (Quest International), $5 \mathrm{mg} / \mathrm{L}$ each of insulin and transferrin (Sigma, St. Louis, MO).

Batch cultures were carried out in $50 \mathrm{~mL}$ conical flasks, unless otherwise noted. The working volume in these experiments was $20 \mathrm{~mL}$. The cycloheximide experiments were carried out with 6-well plates with $2 \mathrm{~mL}$ of cell suspension per well. Cells were grown in an incubator maintained at $37^{\circ} \mathrm{C}, 95 \%$ humidity and $5 \%(\mathrm{v} / \mathrm{v}) \mathrm{CO}_{2}$. For all experiments mid-log phase cells were centrifuged and resuspended in fresh medium at an initial density of $2 \times 10^{5}$ cells $/ \mathrm{mL}$. All experiments were carried out in duplicate. Cell number and viability were assessed by the Trypan blue exclusion assay using a hemacytometer. Extent of apoptosis was determined by the acridine orange/ethidium bromide (AO/EB) assay (McGahon et al., 1995; Mercille and Massie, 1994) using a hemacytometer. In each of the assays at least 200 cells were counted for each sample.

\section{Preparation of Plasmids and Transfection of Cells}

hbcl-2 cDNA (graciously donated by Stanley Korsmeyer, University of Washington) was excised using EcoR1 sites, inserted into pcDNA3.1+ vector (Stratagene, Quest International, Norwich, NY), and placed under the control of a constitutive CMV promoter. Chinese hamster ovary cells grown in suspension were transfected in standard 6-well plates using lipofectamine (GIBCO-BRL). Expression was verified by Western blot analysis using a purified hamster anti-human bcl-2 monoclonal antibody (catalog \#15131A, Pharmingen). The control cell line used was one transfected with the null pcDNA3.1+ vector. Six hundred $\mu \mathrm{g} / \mathrm{mL}$ G-418 (Genetecin, GIBCO-BRL) was used to maintain selective pressure on the mixed culture of cells.

\section{Measurement of Caspase Activity}

About $2 \times 10^{6}$ cells were lysed using a single detergent lysis buffer (Sambrook et al., 1989). Cells from an apoptotic culture were taken for measurement of caspase activity. The substrate used to detect caspases, z-YVAD.AFC (AFC-120, Enzyme Systems Products), has a fluorescent 7 amino-4 trifluromethyl coumarin (AFC) residue. $\mathrm{z}-\mathrm{YVAD}$.AFC is a specific substrate for cysteine proteases within the cell. Cleavage of this substrate after the aspartate residue releases the fluorescent AFC fragment of the protein, which, in turn, leads to fluorescence. To measure fluorescence, $120 \mu \mathrm{L}$ of AFC buffer (50 mM HEPES pH 7.5, $1 \%$ sucrose, $0.1 \%$ CHAPS), $50 \mu \mathrm{L}$ dithiothreitol (100 mM DTT stock), and 10 $\mu \mathrm{L}$ of AFC-120 [2.5 mM AFC-120 in dimethyl sulfoxide (DMSO)] were added to a cuvette, which was then placed in a fluorimeter. The fluorimeter was then zeroed (excitation frequency $=400 \mathrm{~nm}$, emission frequency $=505 \mathrm{~nm}$ ). Twenty $\mu \mathrm{L}$ of the cell lysate was then added to the cuvette and the fluorescence was then monitored with time.

Caspase activity was also measured observing cleavage of Caspase 3 (CPP32) substrate, Poly-ADP-Ribose Polymerase (PARP). PARP cleavage was determined by Western blot analysis of cell lysate using a polyclonal antibody 
against PARP (Boehringer Mannheim, catalog \#1 835 238). Uncleaved PARP runs as a $113 \mathrm{kDa}$ band, while cleaved PARP is detected either as a $89 \mathrm{kDa}$ fragment or a $24 \mathrm{kDa}$ fragment.

\section{Caspase-Inhibiting Peptide Experiments}

z-VAD.fmk (N-benzyloxycarbonyl-Val-Ala-Asp-fluoromethyl-ketone, FK-009, Enzyme Systems Products) was solubilized in dimethyl sulfoxide to yield a stock concentration of $10 \mathrm{mM}$. z-VAD.fmk binds irreversibly to several caspases within the cell. A final concentration of $60 \mu M$ was used for the experiments.

\section{Western Blot Analysis}

About $2 \times 10^{6}$ were lysed in $1 \%$ Triton X-100, $0.15 \mathrm{mM}$ $\mathrm{NaCl}$, and $10 \mathrm{~m} M$ Tris (pH 7.4) with $50 \mu \mathrm{g} / \mathrm{mL}$ phenyl methanesulfonyl fluoride (PMSF) and $2 \mu \mathrm{g} / \mathrm{mL}$ aprotinin. The cell lysates were boiled in sodium dodecyl sulfate (SDS) sample buffer (Sambrook et al., 1989) for $5 \mathrm{~min}$ before being run on a $10 \%$ SDS-polyacrilimide gel (Bio$\mathrm{rad})$. Lysate from $1 \times 10^{5}$ cells was loaded into each lane. Gels were transferred to nitrocellulose filters at $100 \mathrm{~V}$ for 45 min. Blots were blocked with 5\% skim milk overnight and protein was then detected using the appropriate antibody.

\section{DNA Ladder Technique for Detection of Apoptosis}

The Apoptotic DNA Ladder Kit from Boehringer Mannheim (catalog \#1 835 246) was used to observe the characteristic ladder obtained due to internucleosomal cleavage of DNA in apoptosis. The protocol for this assay is well described in the kit. DNA from lysed cells bind to microscopic glass fibers in the presence of a chaotropic salt. The salts are then washed away and the DNA is eluted in Tris buffer and run on a $2 \%$ agarose gel (Sambrook et al., 1989).

\section{Medium Glucose Analysis}

Glucose was analyzed using assay kits from Sigma (catalog \#16-20). This kit was based on enzymatic reactions using hexokinase and glucose-6-phosphate. Samples were deproteinated and neutralized prior to each assay (Xie and Wang, 1993). Absorbance was measured at a wavelength of 340 $\mathrm{nm}$ with a Perkin-Elmer Lambda-3 spectrophotometer.

\section{RESULTS}

\section{CHO Cells Die by Apoptosis in Serum-Free Batch Culture}

The growth kinetics for a typical serum-free batch culture of $\mathrm{CHO}$ cells is shown in Figure 1. After a period of exponential growth cells die very rapidly. There is a small decline in

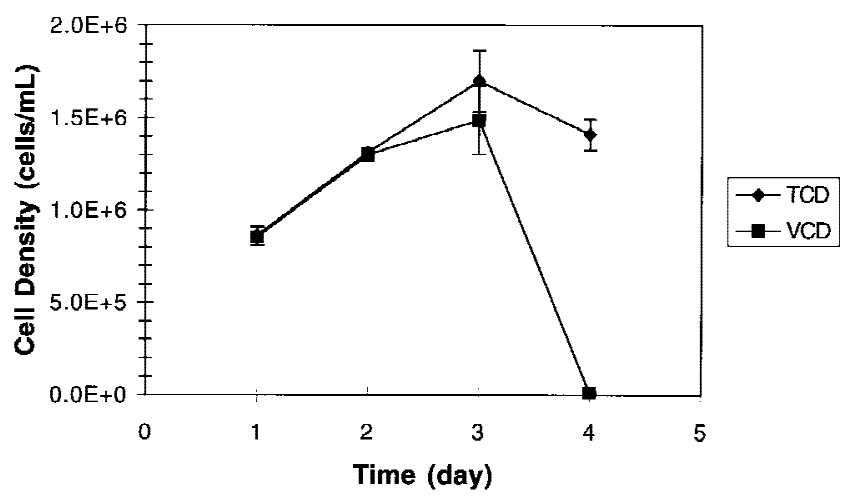

Figure 1. Viable (VCD) and total cell densities (TCD) obtained in normal serum-free batch culture of suspension $\mathrm{CHO}$ cells.

the number of total cells due to the tendency of dead cells to stick to the walls of the flask.

The mode of death involved in these cells, as measured by the AO/EB assay, is shown in Figure 2a. The apoptotic cells included both early (chromatin condensation but no loss in membrane integrity) and late (chromatin condensation and membrane integrity loss) stages of apoptosis. These results indicate that apoptosis is the main mode of death right from the start of the culture growth process, which is in agreement with the work of Moore et al., 1995. Furthermore, apoptosis accounts for more than $95 \%$ of the death occurring during cultivation. In contrast, necrosis accounts for less than $5 \%$ of the final death observed. Apoptosis was also confirmed by the presence of a DNA ladder, when genomic DNA extracted from apoptotic CHO cells was run on an agarose gel (Fig. 2b).

\section{Protein Synthesis Inhibition Causes Rapid, Dose-Dependent Apoptosis in CHO Cells}

Because apoptosis is a genetically controlled form of death where the fate of a cell is determined by death-suppressing and death-inducing proteins, we were interested in determining which class of proteins dominated in $\mathrm{CHO}$ cells. One way to determine this was to inhibit protein synthesis using a protein synthesis inhibitor such as cycloheximide, and then follow the fate of the cells. Two scenarios are possible. In the first scenario, if death proteins are present in greater abundance and survival proteins have to be continuously synthesized to keep the cell alive, prevention of protein synthesis would cause apoptosis. In the second scenario, if death proteins have to be synthesized de novo to initiate apoptosis, inhibition of protein synthesis will ultimately lead to death by necrosis. As shown in Figure 3, we observed extensive and rapid apoptosis, and almost no necrosis on inhibition of protein synthesis. Within $19 \mathrm{~h}$ after the start of protein synthesis inhibition, more than $85 \%$ of the cells with $60 \mu M$ cycloheximide had undergone apoptosis. By contrast, there was less than $8 \%$ apoptosis in the control culture (without cycloheximide). The extent of apoptosis at any point in time was also observed to be dose 


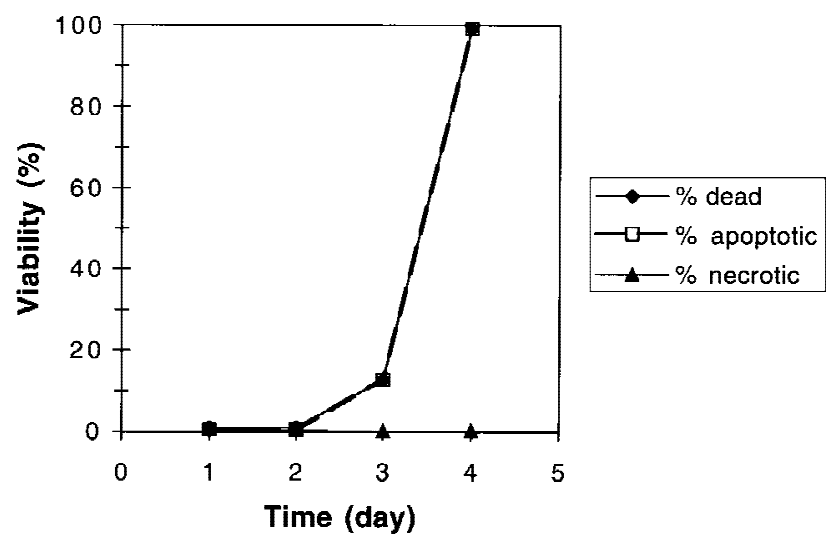

(a)

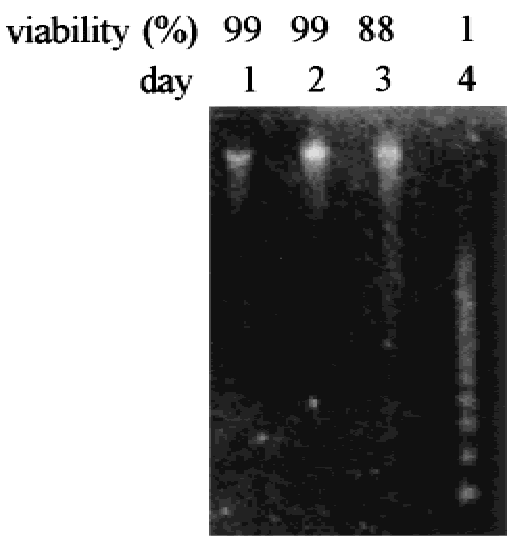

(b)

Figure 2. Apoptosis in batch cultures of CHO cells. (a) Percentage of dead, apoptotic and necrotic cells obtained during a normal serum-free batch culture of CHO cells. The percentage of dead cells is obtained by adding the percentages of apoptotic and necrotic cells. Almost all death is seen to occur via apoptosis. (b) Agarose gel photograph of genomic DNA from CHO cells shows presence of a DNA ladder, which coincides with massive apoptosis.

dependent, with higher levels of cycloheximide resulting in more apoptosis. Similar results were obtained with another protein synthesis inhibitor, actinomycin D (data not shown). Hence, survival proteins must be continuously synthesized to prevent $\mathrm{CHO}$ cells from death.

\section{ICE-Like Protease Inhibiting Peptides Are Unable to Significantly Enhance Viability of CHO Cells in Culture}

ICE-like cysteine proteases (caspases) have been found to be downstream effectors of apoptosis in a large number of cell lines, including $\mathrm{CHO}$ cells. We were interested in determining whether our $\mathrm{CHO}$-cell line expressed some of these proteins in response to stresses resulting from normal cultivation conditions. Using the assay described above (Materials and Methods) we detected caspase activity only in apoptotic CHO cells (Fig. 4). Detection of cleavage of caspase 3 (CPP32/Yama) substrate PARP with death, provided additional support of caspase activity in apoptotic CHO cells (see Fig. 5d).

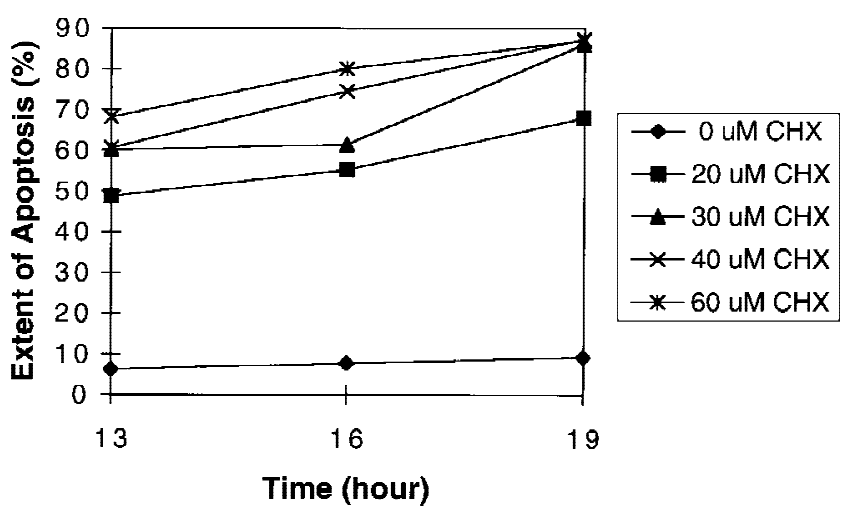

Figure 3. Extent of apoptosis induced by varying doses of cycloheximide (CHX). Cycloheximide induces protein-synthesis inhibition in cells. Apoptosis accounted for almost all the death observed.
With cysteine protease activity detected in our cells, we attempted to delay apoptosis in our cells by adding specific caspase inhibiting peptides to our culture. The peptide we chose was a fluoro-methyl-ketone (fmk) with a sequence, z-Val-Ala-Asp-fmk. This is an irreversible inhibitor of cysteine proteases (Enari et al., 1996; Martin et al., 1996; Takahashi and Earnshaw, 1996; Thornberry and Molineaux, 1995; Wang et al., 1995; Wang et al., 1996). We added 60 $\mu M \mathrm{z}-\mathrm{VAD}$.fmk (solubilized in dimethyl sulfoxide) to batch cultures to examine whether we could delay the rapid death observed at the end of a batch culture. To the control culture for each of these experiments, we added the same volume of DMSO as was used to deliver the z-VAD.fmk.

The results are shown in Figures 5a and b. z-VAD.fmk provides only a small improvement in culture viability $96 \mathrm{~h}$ into the culture. The cause of death at the end of the culture is thought to be primarily glucose depletion, though other factors cannot be ruled out (Fig. 5c). The results demonstrate that the viabilities and cell densities of the two cultures are almost identical for a period of $72 \mathrm{~h}$. Death starts

\section{ICE-like Protease Activity Detected Using YVAD- Flourescent Substrate}

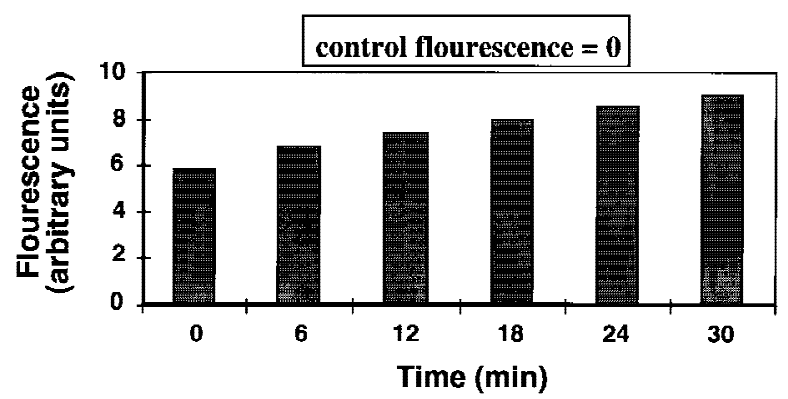

Figure 4. Fluorescence obtained by combining cell-lysate from apoptotic $\mathrm{CHO}$ cells with a fluorescent substrate z-YVAD.AFC, indicating the presence of caspases. 


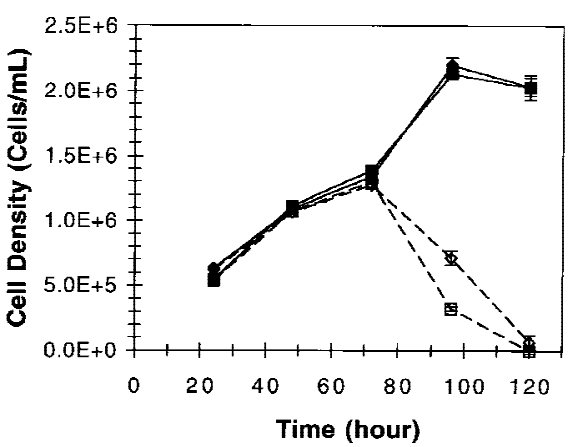

(a)

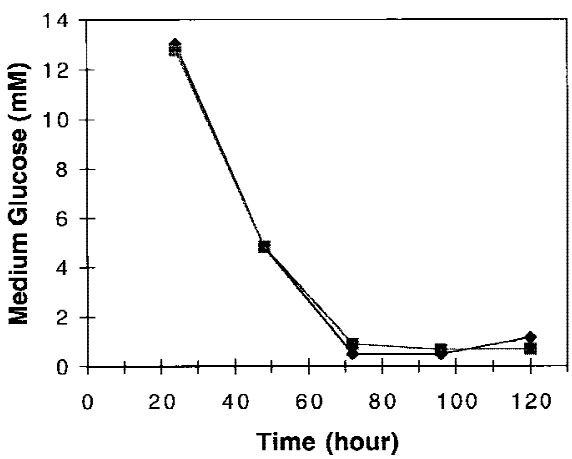

(c)

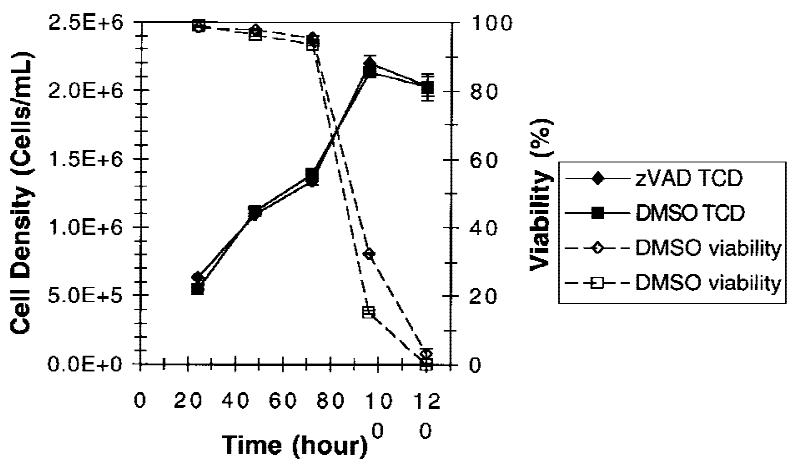

(b) DMSO zVAD DMSO zVAD

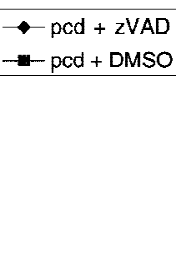

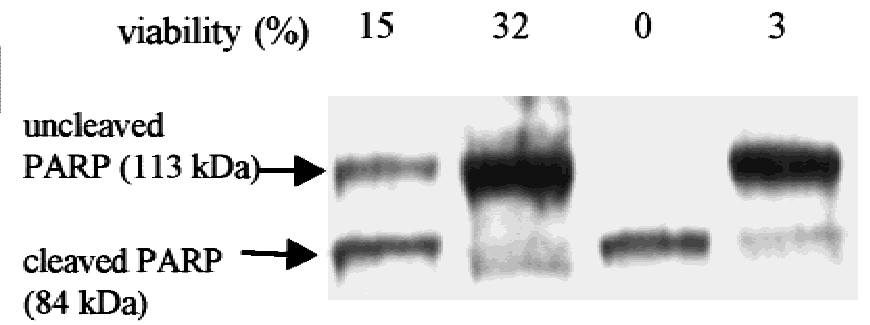

(d)

Figure 5. Comparison of the protective effect of z-VAD.fmk (a peptide inhibitor of caspases) on protected (pcd $+\mathrm{zVAD}$ ) and control (pcd + DMSO) batch cultures of CHO cells: (a) Total cell density (TCD) and viable cell density (VCD) as a function of time. (b) Total cell density and viability of cultures as a function of time. Viability declines rapidly after $72 \mathrm{~h}$. (c) Medium glucose concentration as a function of time. Medium glucose concentration has dropped to almost 0 after $72 \mathrm{~h}$ in both cultures. (d) Poly-ADP-ribose polymerase (PARP) cleavage evident in the control cultures but not in the $\mathrm{z}$-VAD.fmk protected cultures.

to occur almost $24 \mathrm{~h}$ after glucose depletion has set in. We verified that $\mathrm{z}-\mathrm{VAD}$.fmk does get into the cells and prevent cleavage of substrates of caspases by monitoring the cleavage of PARP at 96 and 120 h. Figure 5d shows that there is no cleavage of PARP in the $\mathrm{z}-\mathrm{VAD}$.fmk protected cultures, while a clear cleavage of PARP is seen in the cultures not protected by z-VAD.fmk. Thus, the meager protection in cultures supplemented with z-VAD.fmk cannot be attributed to the inability of $\mathrm{z}-\mathrm{VAD}$.fmk to penetrate the cells. In addition, because the control and z-VAD.fmk protected cultures behave almost identically until the cultures start to die, death in the culture with z-VAD.fmk is not due to any toxic side effect of the peptide.

\section{Bcl-2 Extends Viability in Batch Cultures of CHO Cells}

A mixed culture of $\mathrm{CHO}$ cells transfected with the human bcl-2 gene was used to examine the effect of bcl-2 expression on cell death at the end of a batch culture. The results are shown in Figure 6. The fluctuation in total cell densities at the end of the culture results from a tendency of cells to clump and stick to the walls of the flask. The bcl-2 culture is more than $40 \%$ viable $72 \mathrm{~h}$ after the control culture is completely dead. As can be seen from Figure 6a, bcl-2 expression does not affect the growth rate of the culture. The death stimulus is most probably glucose depletion (Fig. 6c) and in the control culture death sets almost $24 \mathrm{~h}$ after glucose is depleted. In addition, we checked whether bcl-2 expression is able to block cleavage of caspase substrate PARP. Figure 6d shows that even after $168 \mathrm{~h}$ the PARP in the bcl-2 protected cultures remains essentially uncleaved, suggesting that bcl-2 protects against CPP32 activity in CHO cells. We suspect that the small band of cleaved PARP which appears in the bcl-2 lane, may be caused by apoptosis in the mixed population of cells which do not express bcl-2. The protective effect of bcl-2 is similar to that observed by authors using other cell lines (Itoh et al., 1995; Simpson et al., 1997; Singh et al., 1997; Suzuki et al., 1997; Terada et al., 1997).

\section{Bcl-2 Protects Better Than Caspase-Inhibiting Peptides in Response to Growth and Survival Factor Withdrawal}

Growth and survival factor withdrawal is known to be a potent inducer of apoptosis in mammalian cells, especially in the absence of serum (Bottenstein et al., 1979; Murakami, 1989; Zhou and $\mathrm{Hu}, 1995)$. Insulin and transferrin were used as specific growth and survival factors used in our serum-free medium. We studied the protective effect of bcl-2 and z-VAD.fmk separately and together in protecting $\mathrm{CHO}$ cells in batch culture from the effects of insulin and transferrin withdrawal. A volume of DMSO equal to that 


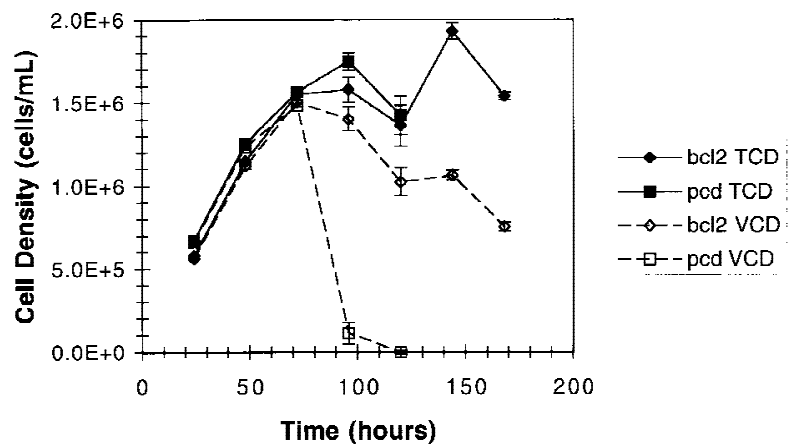

(a)

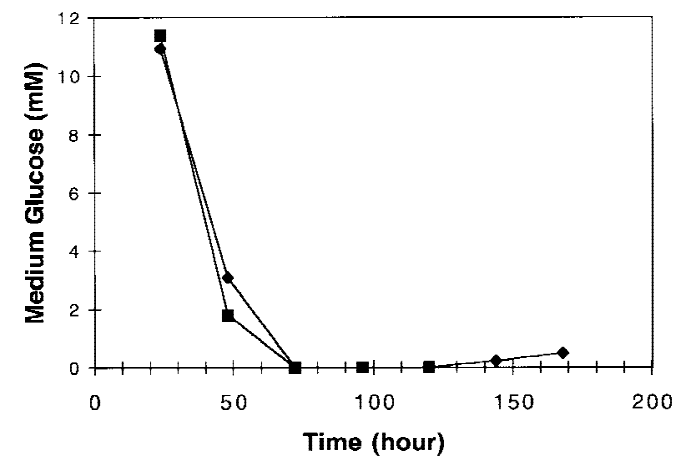

(c)

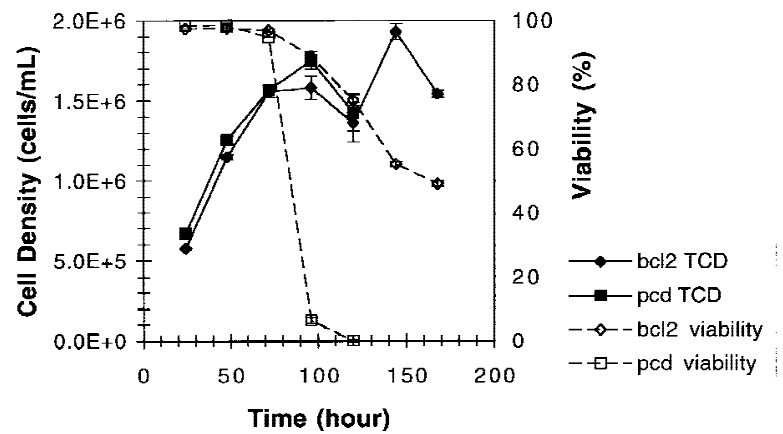

(b)

cell line time (hour) viability $\rightarrow-\mathrm{bcl} 2$

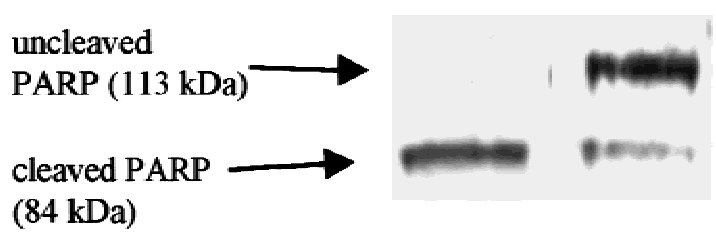

(d)

Figure 6. Protective effect of bcl-2 expression as compared to a control (pcd) in batch culture of CHO cells: (a) Total cell density (TCD) and viable cell density (VCD) as a function of time. (b) Total cell density and viability of cultures as a function of time. Viability of the control, but not the bcl-2 protected cell line, declines rapidly after $72 \mathrm{~h}$. (c) Medium glucose concentration as a function of time. Medium glucose concentration has dropped to almost 0 after $72 \mathrm{~h}$ in both cultures. (d) Poly-ADP-ribose polymerase (PARP) cleavage is clearly evident in the control cultures, but almost all the PARP is uncleaved in the bcl-2 protected cultures.

used to deliver the z-VAD.fmk to the other cultures was added to the control (pcd-CHO) culture and the bcl-2-CHO culture. The results of the experiment are shown in Figure 7. The potency of insulin and transferrin withdrawal in initiating apoptosis can be judged from the rapid death in the control culture (pcd + DMSO). It is seen that bcl-2 and $\mathrm{z}-\mathrm{VAD}$.fmk acting together do, indeed, provide better protection than either agent alone. Also, bcl-2 expression provides much better protection than adding z-VAD.fmk to the culture. The sudden decrease in viability for the pcd $+\mathrm{z}-$ VAD.fmk culture at $72 \mathrm{~h}$ is probably due to the exhaustion of glucose in the culture (Fig. 7c). The better growth rates of the z-VAD.fmk supplemented cultures (Fig. 7a) cannot be explained at this time.

\section{DISCUSSION}

There have been conflicting reports in literature as to the mode of death in CHO cells (Moore et al., 1995; Moore et al., 1997; Singh et al., 1994; Singh et al., 1997). In this article, we have shown that $\mathrm{CHO}$ cells grown in batch culture die via apoptosis; a form of genetically encoded death. In batch culture, this induction of apoptosis followed the depletion of glucose in the medium. In addition, we have also demonstrated, by means of protein synthesis inhibition, that de novo protein synthesis is not necessary for $\mathrm{CHO}$ cells to undergo apoptosis. This implies that death-inducing and death-suppressing proteins are always present within the $\mathrm{CHO}$ cell, and that possibly death proteins degrade less rapidly than survival proteins (Mercille and Massie, 1994; Mosser and Massie, 1994). Hence, when protein synthesis is inhibited, death proteins are able to exert their effect once the survival proteins have been removed. This hypothesis also implies that in a surviving $\mathrm{CHO}$ cell, survival proteins have to be continuously synthesized to enable the cell to escape death. This scenario lends support to our hypothesis that overexpression of the correct survival protein or inhibition of the death proteins in the $\mathrm{CHO}$ cell may be able to delay the onset of apoptosis in response to certain stress stimuli.

ICE-like cysteine protease (caspase) activity was detected in $\mathrm{CHO}$ cells. Therefore, our first effort was to determine if countering the effect of cysteine proteases within the cell would be able to extend the life of a batch culture. Experiments were carried out using z-VAD.fmk, a cysteine protease-inhibiting peptide. This peptide, though not the most potent inhibitor, was chosen because it is known to have better cell membrane permeability. Our experiments indicate that inhibition of caspases is able to marginally delay the onset of apoptotic death in batch culture of CHO cells. When apoptotic stimuli such as withdrawal of insulin and transferrin were introduced, cell cultures with z-VAD.fmk exhibited a higher viability, with respect to the control. This protective effect was observed right from the start of the culture. However, viability rapidly declined as medium glu- 


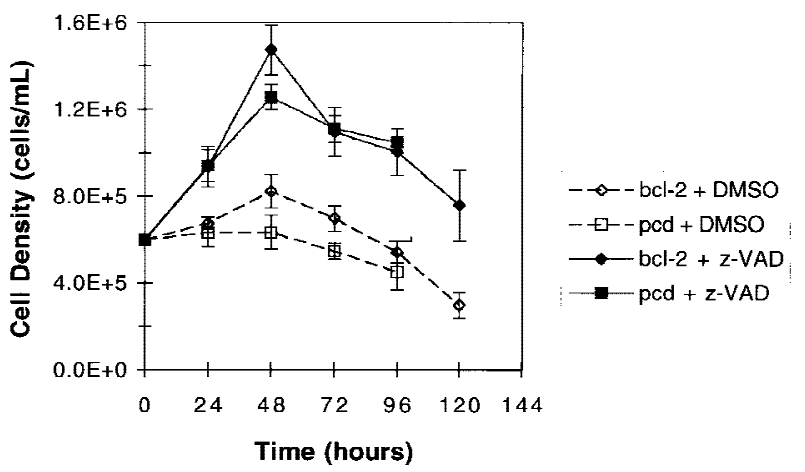

(a)

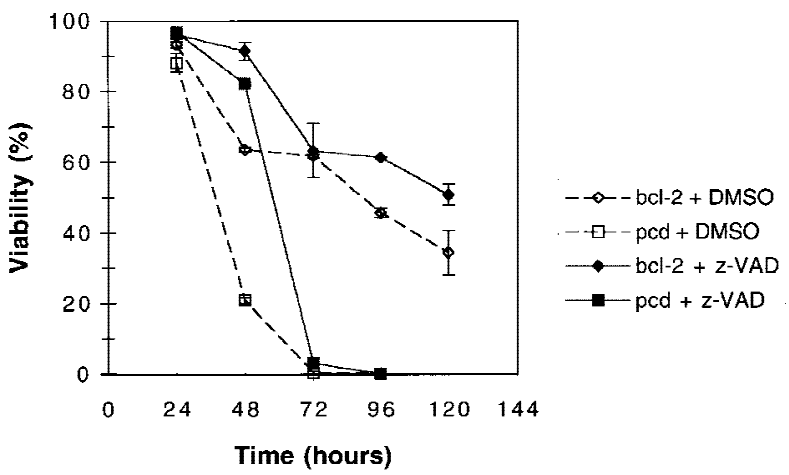

(b)

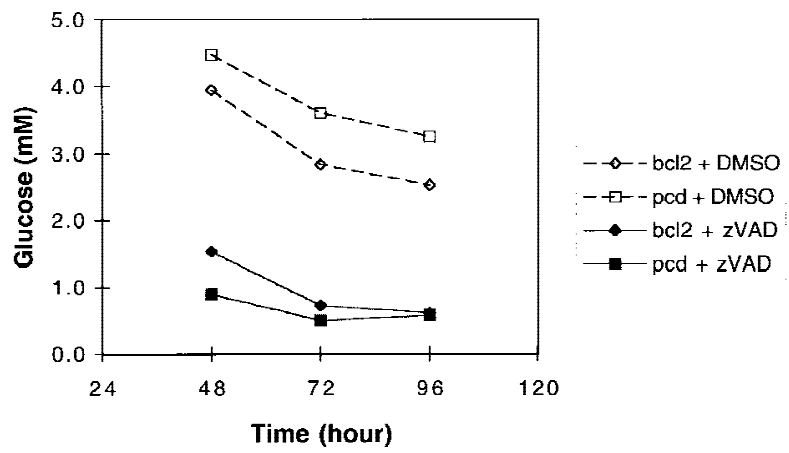

(c)

Figure 7. Comparison of the protective of bcl-2 expression and zVAD.fmk, together and separately, in batch cultures of CHO cells which have been deprived of insulin and transferrin. To cultures which did not contain $\mathrm{z}$-VAD.fmk we added a volume of dimethyl sulfoxide (DMSO) equal to the volume that was used to deliver z-VAD.fmk to the other cultures (also see text). (a) Total cell density (TCD) as a function of time. (b) Viability of cultures as a function of time. (c) Medium glucose concentration as a function of time.

cose concentrations fell to near 0 , suggesting limits to the protective effect of z-VAD.fmk.

Other experiments were conducted to determine whether overexpression of bcl-2, a well-studied death-suppressing gene, in $\mathrm{CHO}$ cells would be able to extend the life of batch cultures. Bcl-2 has been shown to have a protective effect under cell-culture conditions in several other cell lines (Itoh et al., 1995; Mastrangelo and Betenbaugh, 1998; Mastrangelo et al., 1996; Simpson et al., 1997; Singh et al., 1996; Singh et al., 1997; Suzuki et al., 1997; Terada et al., 1997). In the case of both normal and insulin- and transferrin- deprived $\mathrm{CHO}$ batch cultures, bcl-2 was able to delay the onset of apoptosis substantially. It is interesting to note that both bcl-2 and z-VAD.fmk only start to play a role once apoptotic stimuli are experienced. The growth and viability of the control culture is identical to that of the protected culture before the appearance of apoptotic stimuli.

$\mathrm{Bcl}-2$ overexpression seems to be a better way to extend the life of $\mathrm{CHO}$ cultures than using caspase inhibitors. This is interesting, especially because the point of action of bcl-2 appears to be upstream of that of the caspases in the apoptotic pathway (Enari et al., 1996; Wang et al., 1996) (Fig. $8 \mathrm{a})$. We were interested in determining if having both bcl-2 and $z$-VAD.fmk together provided any additional protection over just having z-VAD.fmk alone in the culture. If certain caspase-independent pathways exist, and bcl-2 is also able to block these pathways, then having both bcl-2 and caspase inhibitors should improve culture viability. Figure $7 \mathrm{~b}$ shows that bcl-2 and z-VAD.fmk acting together do indeed provide better protection than either agent alone. This improved survival could not have been due to z-VAD.fmk protection of the non-bcl-2 expression cells in the mixed culture; we know that $z$-VAD.fmk alone is unable to protect cells not expressing bcl-2, once glucose is exhausted (Figs. $7 \mathrm{~b}$ and c). Hence, bcl-2 independent and caspase-dependent pathways appear to exist.

Our results are bolstered by reports in literature about two separate apoptotic pathway factors that bcl-2 is able to block cytochrome c (Kluck et al., 1997; Liu et al., 1996; Yang et al., 1997) and Apoptotic-Inducing Factor (AIF) (Kroemer et al., 1997; Susin et al., 1996). It is suggested that both these factors reside between the inner and outer membranes of the mitochondria. They are released in response to apoptotic stimuli, whereupon they initiate subsequent steps in the apoptotic pathway. Bcl-2, by virtue of its subcellular localization to the mitochondrial membrane, is able to block apoptotic death purely by blocking the release of these agents from the mitochondria. Cytochrome $\mathrm{c}$ has been shown to activate cysteine proteases. The pathway by which

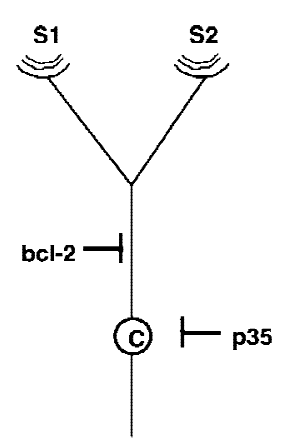

a)

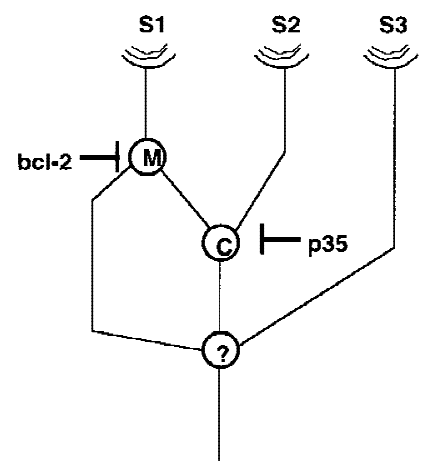

b)
Figure 8. Possible pathways of death in the $\mathrm{CHO}$ cell, focusing on the bcl-2 and cysteine protease nodes. (a) Conventional pathway. (b) Suggested pathway. S1, S2, and S3 are the same or different external stimuli for apoptosis. M, C, and "??" are the mitochondrial, cysteine protease, and as yet unknown checkpoints for apoptosis, respectively. 
AIF causes apoptosis seems to be caspase independent. Given this information and the fact that bcl-2 has been shown to act upstream of caspases in the apoptotic pathway, we have attempted to come up with an apoptotic pathway in $\mathrm{CHO}$ cells which focuses on bcl-2 and caspases (Fig. 8b). As indicated by the pathway emanating from stimulus $\mathrm{S} 1$ and reaching the mitochondrial checkpoint for apoptosis, blocking caspase activity using caspase inhibitory peptides will not block apoptosis occurring via the AIF pathway, but expressing bcl-2 within the cell will. This part of the proposed pathway partially explains why we observe that bcl-2 and $\mathrm{z}-\mathrm{VAD}$.fmk together provide greater protection than $\mathrm{z}$-VAD.fmk alone. In addition, it is possible that some elements of the apoptotic pathway bypass the bcl-2 node and directly activate caspases, as indicated by the sequence of events triggered by stimulus $\mathrm{S} 2$. This hypothesis would explain our other observation as to why bcl-2 and z-VAD.fmk together provide better protection than bcl-2 alone.

The fact that cells still die despite the presence of both z-VAD.fmk and bcl-2, can be explained by one or both of the following hypotheses. First, as the level of insults gets progressively greater, it is possible that the level of bcl-2 and/or z-VAD.fmk in the cell is no longer sufficient to counter the levels of the death-protagonist elements of the apoptotic pathway. Second, pathways that are both bcl-2 and caspase independent, as indicated by the pathway triggered by stimulus S3, may exist. This pathway may directly trigger events at an as yet unidentified node (indicated by "'?') in the apoptotic pathway, which is downstream of the mitochondrial and caspase checkpoints. At this point, we have no evidence to allow us to choose between these two hypotheses. It must be emphasized that S1, S2, and S3 may be the same or different stimuli, and choice of the pathway of action may depend on the level of the insult to the cell.

The drawback with studies carried out in the batch mode is that cultures invariably are exposed to a nutrient limitation, which ultimately proves to be too strong a stimulus to counter using either gene expression or peptide-induced inhibition of caspases. This observation corroborates batchculture results presented by other authors working with several cell lines (Itoh et al., 1995; Simpson et al., 1997; Singh et al., 1996; Singh et al., 1997; Suzuki et al., 1997). Furthermore, this scenario of nutrient limitation is unlikely to occur industrially. Fed-batch studies, currently underway in our lab, in which nutrient limitation ceases to be a primary cause of death, will provide an interesting environment in which to further test the protective effect of deathsuppressing proteins such as bcl-2 and caspase-inhibiting peptides. In addition, these studies will give us an opportunity to study the effect of bcl-2 expression on total product titers in an environment where nutrient availability is not a limiting factor.

\section{References}

Bissonnette RP, Echeverri F, Mahboubi A, Green DR. 1992. Apoptotic cell death induced by c-myc is inhibited by bcl-2. Nature 359:552-554.
Bottenstein J, Hayashi I, Huchings S, Masui H, Mather J, McClure D, Ohasa S, Rizzino A, Sato G, Serrero G, Wolfe R, Wu R. 1979. The growth of cells in serum-free hormone supplemented media. In: Jackoby WB and Pastan IH, editors. Methods in enzymology. New York: Academic Press. p 175-204.

Chinnaiyan AM, Dixit VM. 1996. The cell-death machine. Curr Biol 6: 555-562.

Chiou SK, Rao L, White E. 1994. Bcl-2 blocks p53-dependent apoptosis. Mol Cell Biol 14:2256-2263.

Cuende E, Alès-Martinez JE, Ding L, Gûnzalez-Garcìa M, Martìnez AC, Nunez G. 1993. Programmed cell death by bcl-2-dependent and independent mechanisms in B lymphoma cells. EMBO J. 12:1555-1560.

Enari M, Talanian RV, Wong WW, Nagata S. 1996. Sequential activation of ICE-like and CPP32-like proteases during fas-mediated apoptosis. Nature 380:723-726.

Fanidi A, Harrington EA, Evan, GI. 1992. Cooperative interaction between c-Myc and bcl-2 oncogenes. Nature 359:554-556.

Farrow SN, Brown R. 1996. New members of the Bcl-2 family and their protein partners. Curr Opinion Gen Dev 6:45-49.

Fernandes-Alnemri T, Takahashi A, Armstrong R, Krebs J, Fritz L, Tomaselli KJ, Wang L, Yu Z, Croce CM, Salveson G, Earnshaw WC, Litwack G, Alnemri ES. 1995. Mch3, a novel human apoptotic cysteine protease highly related to CPP32. Can Res 55:6045-6052.

Franek F. 1995. Starvation-induced programmed death of hybridoma cells: Prevention by amino acid mixtures. Biotechnol Bioeng 45:86-90.

Franek F, Chladkova-Sramkova K. 1995. Apoptosis and nutrition: Involvement of amino acid transport system in repression of hybridoma cell death. Cytotechnol 18:113-117.

Gottschalk AR, Boise LH, Thompson CB, Quintens J. 1994. Identification of immunosuppressant-induced apoptosis in a murine B-cell line and its prevention by bcl-x but not bcl-2. Proc Natl Acad Sci USA 91: 7350-7354.

Hockenberry DM, Oltvai ZN, Yin X, Milliman CL, Korsmeyer SJ. 1993. $\mathrm{Bcl}-2$ functions in an antioxidant pathway to prevent apoptosis. Cell 75:241-251.

Itoh Y, Ueda H, Suzuki E. 1995. Overexpression of bcl-2, apoptosis suppressing gene: Prolonged viable culture period of hybridoma and enhanced antibody production. Biotechnol Bioeng 48:118-122.

Jacobson MD, Burne JF, King MP, Miyashita T, Reed JC, Raff MC. 1993. Apoptosis and $\mathrm{Bcl}-2$ protein in cells without mitochondrial DNA. Nature (Lond.) 361:365-368.

Kluck RM, Bossy-Wetzel E, Green DR, Newmeyer DD. 1997. The release of cytochrome $\mathrm{c}$ from mitochondria: A primary site for Bcl-2 regulation of apoptosis. Science 275:1132-1136.

Korsmeyer SJ. 1992. Bcl-2: A repressor of lymphocyte death. Immunol Today 13:285-288.

Kroemer G, Zamzami N, Susin SA. 1997. Mitochondrial control of apoptosis. Immunol Today 18:44-51.

Lam M, Dubyak G, Chen L, Nuñez G, Miesfeld RL, Distelhorst CW. 1994. Evidence that bcl-2 represses apoptosis by regulating endoplasmic reticulum-associated $\mathrm{Ca}^{++}$fluxes. Proc Natl Acad Sci USA 91: 6569-6573.

Lazebnik YA, Kaufmann SH, Desnoyers S, Poirier GG, Earnshaw WC. 1994. Cleavage of poly(ADP-ribose) polymerase by a proteinase with properties like ICE. Nature 371:346-347.

Liu X, Kim CN, Yang J, Jemmerson R, Wang X. 1996. Induction of apoptotic program in cell-free extracts: Requirement for dATP and cytochrome c. Cell 86:147-157.

Lotem J, Sachs L. 1993. Regulation by bcl-2, c-Myc, and p-53 of susceptibility to induction of apoptosis by heat shock and cancer chemotherapy compounds in differentiation-component and -defective myeloid leukemic cells. Cell Growth Diff 4:41-47.

Martin SJ, Amarante-Mendes GP, Shi L, Chuang T, Casiano CA, O’Brien GA, Fitzgerald P, Tan EM, Bokoch GM, Greenberg AH, Green DR. 1996. The cytotoxic cell protease granzyme B initiates apoptosis in a cell-free system by proteolytic processing and activation of the ICE/ CED-3 family protease, CPP32, via a novel two-step mechanism. EMBO J 15:2407-2416. 
Martin SJ, Cotter TG. 1994. Apoptosis of human leukemia: Induction, morphology and molecular mechanisms. In: Tomei LD, Cope FO, editors. Apoptosis II: The molecular basis of apoptosis in disease. Cold Spring Harbor, NY: Cold Spring Harbor Laboratory Press. p 1-91.

Mastrangelo AJ, Betenbaugh MJ. 1998. Overcoming apoptosis: New methods for improving protein-expression systems. TIBTECH 16:88-95.

Mastrangelo AJ, Hardwick JM, Betenbaugh MJ. 1996. Bcl-2 inhibits apoptosis and extends recombinant protein production in cells infected with Sindbis viral vectors. Cytotechnol 22:169-178.

McGahon AJ, Martin SJ, Bisonette RP, Mahboubi A, Yufang S, Mogil RJ, Nishioka WK, Green DR. 1995. The end of the (cell) line: Methods for the study of apoptosis in vitro. In: Schwartz LM and Osborne B, editors. Methods in cell biology. San Diego: Academic Press. p $172-173$.

Mercille S, Massie B. 1994. Induction of apoptosis in nutrient-deprived cultures of hybridoma and myeloma cells. Biotechnol Bioeng 44: 1140-1154.

Moore A, Donahue CJ, Hooley J, Stocks DL, Bauer KD, Mather JP. 1995. Apoptosis in $\mathrm{CHO}$ cell batch cultures: Examination by flow cytometry. Cytotechnol 17:1-11.

Moore A, Mercer J, Dutina G, Donahue CJ, Bauer KD, Mather JP, Etcheverry T, Ryll T. 1997. Effects of temperature shift on cell cycle, apoptosis and nucleotide pools in $\mathrm{CHO}$ cell batch cultures. Cytotechnol 23:47-54

Mosser DD, Massie B. 1994. Genetically engineering mammalian cell lines for increased viability and productivity. Biotech Adv 12:253-277.

Murakami H. 1989. Serum-free media used for cultivation of hybridomas. In: Monoclonal antibodies: Production and applications. New York: Alan R. Liss.

Perreault J, Lemieux R. 1994. Essential role of optimal protein synthesis in preventing the apoptotic death of B cell hybridomas. Cytotechnol 13: 99-105.

Reed JC. 1994. Bcl-2 and the regulation of programmed cell death. J Cell Biol 124:1-6.

Ruoslahti E, Reed JC. 1994. Anchorage dependence, integrins, and apoptosis. Cell 77:477-478.

Sambrook J, Fritsch EF, Maniatis T. 1989. Molecular cloning, 2nd edition. Cold Spring Harbor, NY: Cold Spring Harbor Laboratory Press.

Scahill SJ, Devos R, van der Heyden J, Fiers W. 1983. Expression and characterization of the product of a human immune interferon cDNA gene in Chinese hamster ovary cells. Proc Natl Acad Sci USA 80 4654-4658.

Simpson NJ, Milner AE, Al-Rubeai M. 1997. Prevention of hybridoma cell death by bcl-2 during suboptimal culture conditions. Biotechnol Bioeng 54:1-16.

Singh RP, Al-Rubeai M, Gregory CD, Emery AN. 1994. Cell death in bioreactors: A role for apoptosis. Biotechnol Bioeng 44:720-726.
Singh RP, Emery AN, Al-Rubeai M. 1996. Enhancement of survivability of mammalian cells by overexpression of the apoptosis-suppressor gene bcl-2. Biotechnol Bioeng 52:166-175.

Singh RP, Finka G, Emery AN, Al-Rubeai M. 1997. Apoptosis and its control in cell culture systems. Cytotechnol 23:87-93.

Susin SA, Zamzami N, Castedo M, Hirsch T, Marchetti P, Macho A, Daugas E, Geuskens M, Kroemer G. 1996. Bcl-2 inhibits the mitochondrial release of an apoptogenic protease. J Exp Med 184: 1331-1341.

Suzuki E, Terada S, Ueda H, Fujita T, Komatsu T, Takayama S, Reed JC. 1997. Establishing apoptosis resistant cell lines for improving protein productivity of cell culture. Cytotechnol 23:55-59.

Takahashi A, Earnshaw WC. 1996. ICE-related proteases in apoptosis. Curr Op Gen Dev 6:50-55.

Terada S, Itoh Y, Ueda H, Suzuki E. 1997. Characterization and fed-batch culture of hybridoma overexpressing apoptosis suppressing gene bcl-2. Cytotechnol 24:135-141.

Tewari M, Quan LT, O'Rourke K, Desnoyers S, Zeng Z, Beidler DR, Poirier GG, Salvesen GS, Dixit VM. 1995. Yama/CPP32 $\beta$, a mammalian homolog of CED-3, is a CrmA-inhibitable protease that cleaves the death substrate poly(ADP-Ribose) polymerase. Cell 81:801-809.

Thornberry NA, Molineaux SM. 1995. Interleukin-1- $\beta$ converting enzyme: A novel cysteine protease required for IL-1 $\beta$ production and implicated in programmed cell death. Protein Sci 4:3-12.

Wang L, Miura M, Bergeron L, Zhu H, Yuan J. 1994. Ich-1, an Ice/ced3-related gene, encodes both positive and negative regulators of programmed cell death. Cell 78:739-750.

Wang X, Pai J, Wiedenfeld EA, Medina JC, Slaughter CA, Goldstein JL, Brown MS. 1995. Purification of an Interleukin-1- $\beta$ converting enzyme-related cysteine protease that cleaves sterol regulatory elementbinding proteins between the leucine zipper and transmembrane domains. J Biol Chem 270:18044-18050.

Wang X, Zelenski NG, Yang J, Sakai J, Brown MS, Goldstein JL. 1996. Cleavage of sterol regulatory element binding proteins (SREBPs) by CPP32 during apoptosis. EMBO J 15:1012-1020.

Xie L, Wang DIC. 1993. Fed-batch cultivation of animal cells using different medium design and feeding strategies. Biotechnol Bioeng 43: 1175-1189.

Yang J, Xuesong L, Bhalla K, Kim CN, Ibrado AM, Cai J, Peng T, Jones DP, Wang X. 1997. Prevention of apoptosis by Bcl-2: Release of cytochrome c from mitochondria blocked. Science 275:1129-1132.

Zhang Z, Vuori K, Reed JC, Ruoslahti E. 1995. The $\alpha 5 \beta 1$ integrin supports survival of cells on fibronectin and up-regulates Bcl-2 expression. Proc Natl Acad Sci USA 92:6161-6165.

Zhou W, Hu W-S. 1995. Effect of insulin on a serum-free hybridoma culture. Biotechnol Bioeng 47:181-185. 